sexual abuse is of the highest standards. Whoever performs the examination should be trained in both paediatrics and forensic techniques and be seeing children regularly.

The scheme was set up initially simply to provide women doctors for those victims who preferred to see a woman. Obviously it is not necessary to be a woman to provide a caring service to victims, but it must not be forgotten that older children and women do prefer a woman doctor - and sometimes insist on one. Any area of the United Kingdom that has no women police surgeons must question the adequacy of its service.

Each police area is different. The Northumbria model would not necessarily be suitable elsewhere.
The success of the scheme, however, shows the possibilities opened up by flexible and creative planning to provide answers for difficult problems. All credit is due to Northumbria police for their innovative thinking and their commitment to the principle of providing a better service for the victims of sexual abuse and to the area's police surgeons for their help and cooperation.

1 Morris RM. Investigations of offences of rape. London: Home Office, March 1983. (Circular 25/10/83.)

2 Cupoli JM, Sewell PM. One thousand fifty nine children with a chief complain of sexual abuse. Child Abuse Neg 1988;12:151-62.

(Accepted 4 January 1989)

\title{
Scottish attitudes to blood donation and AIDS
}

\author{
S G MacAskill, G B Hastings, R E J McNeill, J Gillon
}

\section{Abstract \\ Objective-To see whether the issue of AIDS has influenced the observed decline in blood donation in Scotland.}

Design-Two methods: a quantitative survey using personal interviews based on a questionnaire and a qualitative survey based on group discussions.

Setting-Interviews based on the questionnaire were conducted in the respondents' homes. The group discussions were held in the homes of professional market research interviewers.

Participants-For the quantitative survey a representative sample of 976 Scottish adults was selected by multistage sampling. In the qualitative survey 16 groups of five to eight respondents assigned according to donating experience and sociodemographic criteria took part.

Main results-AIDS was not mentioned as a discouraging factor in donation, and off putting aspects identified before AIDS became a public issue remained salient - for example, fear of needles. Many (75\%) thought it unlikely that donation entailed a risk of developing AIDS. Nevertheless, respondents were reluctant to consider the AIDS issue personally. Being asked to do so, as in the routine screening of donors, aroused fears and resentment.

Conclusions - The issue of AIDS, including fear of infection, has not directly influenced the declining numbers of donors, but the unpleasant associations has decreased such that during 1988-9 the Scottish National Blood Transfusion Service is expected to be unable to meet the clinical demand for factor VIII and albumin products (figure). Of greater importance, however, has been a more pronounced decrease in the numbers of new donors attending, culminating in a fall of $18 \cdot 5 \%$ between $1986-7$ and $1987-8$ (table I).

The first message from the Scottish National Blood Transfusion Service to blood donors about AIDS was issued in August 1983, when those at risk of infection were asked not to give blood. The number of groups at risk was extended as knowledge accumulated. Mass publicity from government and other media sources highlighting blood as a medium for transferring the virus has intensified potential conceptual links between AIDS and blood and hence blood donation and transfusion. In addition, since October 1985 donors throughout the United Kingdom have been required to consent to each donation being tested for antibodies to HIV.

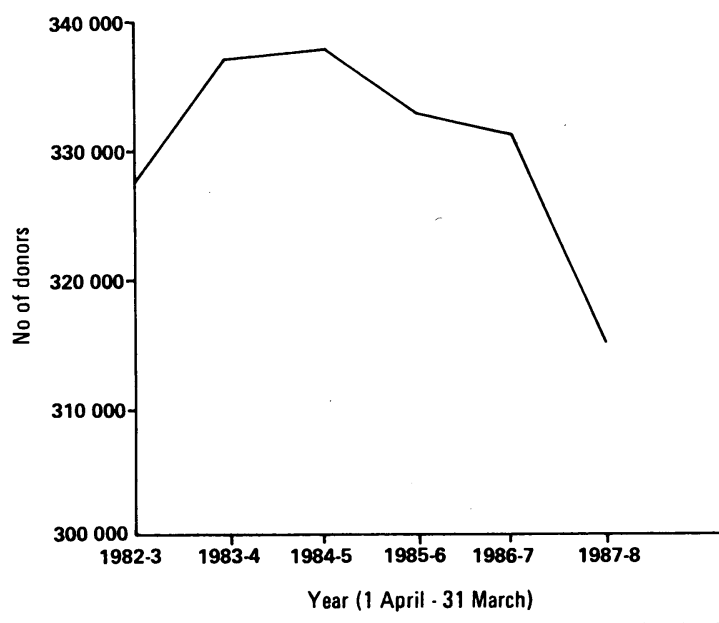

Numbers of donors attending sessions of Scottish National Blood Transfusion Service from 1 A pril 1982 to 31 March 1988

TABLE I-Numbers of new donors bled each year (from 1 April to 31 March) by Scottish National Blood Transfusion Service and percentage change from $1982-3$

\begin{tabular}{lcccccc}
\hline & \multicolumn{6}{c}{ Year } \\
\cline { 2 - 7 } & $1982-3$ & $1983-4$ & $1984-5$ & $1985-6$ & $1986-7$ & $1987-8$ \\
\hline $\begin{array}{l}\text { No bled } \\
\text { \% Change }\end{array}$ & 42975 & 47269 & 45267 & 41146 & 41803 & 34073 \\
& & $+10 \cdot 0$ & $+5 \cdot 3$ & $-4 \cdot 3$ & $-2 \cdot 7$ & $-20 \cdot 7$
\end{tabular}
\begin{abstract}
of AIDS have had an indirect effect, particularly in undermining the emotional benefits of giving blood. For example, the screening process, which requires potential donors to consider their personal risk from AIDS, has had the effect of discouraging donors in general. Redressing the balance is difficult as screening must be universally applied. Rather than minimising the issue of AIDS, publicity needs urgently to reassert the positive benefits of and rewards from giving blood.

\section{Introduction}

One of the many implications of AIDS is the threat it poses to the maintenance of adequate supplies of donated blood.

In Scotland the yearly number of blood donors attending sessions increased steadily from the late 1970s until 1983-4, when the supply of blood and plasma was sufficient to meet the clinical demands. Since 1984-5 the number of attendances by donors

Correspondence to: Ms MacAskill.

BrMed f 1989;298:1012-4

Department of Marketing, Glasersity of Strathc

S G MacAskill, MA, research

fellow

director

Transfusion Service, Sout

Department of Transfusion

Medicine, Royal Infi

J Gillon, MD, consultant

Scottish National Blood

Transfusion Service, South

physician
\end{abstract}

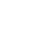


Thus the fall in the number of attendances by donors might be linked to the association between AIDS and blood donation and transfusion. Because of the need to reverse this downward trend the Scottish National Blood Transfusion Service needed to find out whether the screening methods and general publicity about AIDS were exerting direct effects on the motivation of blood donors and whether other related factors - for example, a fear of developing AIDS through blood donation-might be important. The advertising research unit was commissioned to address these questions using information obtained from blood donors and the general public.

\section{Methods}

Quantitative and qualitative methods were used. Quantitative data were collected by using an "omnibus" survey, which is a regularly repeated survey conducted by some commercial agencies on a range of topics, questionnaire space and data processing facilities being sold to clients on a cost per question basis. In our survey a representative sample of Scottish adults (table II) was selected by multistage sampling and all were interviewed in person by experienced market research interviewers. Fieldwork took place in November 1987. Data were obtained on blood donor state, spontaneous perceptions of off putting aspects of donating (before any reference to AIDS), and beliefs about the chances of developing AIDS from donating blood.

The qualitative research entailed bringing together groups of five to eight respondents who had been carefully selected according to sociodemographic criteria into an informal setting. Under the direction of

TABLE III -Composition of each discussion group. All donor groups contained donors from mixture of donor centres, community sessions, and workplaces

\begin{tabular}{clcccc}
\hline Group No & \multicolumn{1}{c}{ Donor state } & $\begin{array}{c}\text { Age range } \\
\text { (years) }\end{array}$ & Sex & Social class & Location \\
\hline 1 & Donor & $18-24$ & Male & A, B, C1 & Glasgow \\
2 & Donor & $18-24$ & Female & C2, D, E & Glasgow \\
3 & Donor & $25-44$ & Female & C2, D, E & Glasgow \\
4 & Donor & $45-65$ & Male & A, B, C1 & Glasgow \\
5 & Lapsed donor and ex-donor & $18-24$ & Male & C2, D, E & Glasgow \\
6 & Non-donor & $18-24$ & Female & A, B, C1 & Glasgow \\
7 & Donor & $18-24$ & Female & A, B, C1 & Edinburgh \\
8 & Donor & $18-24$ & Male & C2, D, E & Edinburgh \\
9 & Donor & $25-44$ & Male & A, B, C1 & Edinburgh \\
10 & Donor & $45-65$ & Female & C2, D, E & Edinburgh \\
11 & Lapsed donor and ex-donor & $18-24$ & Female & A, B, C1 & Edinburgh \\
12 & Non-donor & $18-24$ & Male & C2, D, E & Edinburgh \\
13 & Donor & $18-24$ & Male & A, B, C1 & Aberdeen \\
14 & Donor & $18-24$ & Female & C2, D, E & Aberdeen \\
15 & Donor & $25-44$ & Male & C2, D, E & Aberdeen \\
16 & Donor & $45-65$ & Female & A, B, Cl & Aberdeen \\
& & & & & \\
\hline
\end{tabular}

TABLE IV-Off putting aspects about idea of giving blood in quantitative sample as whole and in different donor subsamples. Weighting was applied during analysis and percentages (numbers) of respondents given are weighted figures

\begin{tabular}{|c|c|c|c|c|c|}
\hline & \multirow[b]{2}{*}{$\begin{array}{c}\text { Total } \\
(\mathrm{n}=976)\end{array}$} & \multicolumn{4}{|c|}{ Donor state ${ }^{\star}$} \\
\hline & & $\begin{array}{l}\text { Current donor } \\
\quad(n=98)\end{array}$ & $\begin{array}{l}\text { Lapsed donor } \\
\qquad(\mathrm{n}=50)\end{array}$ & $\begin{array}{c}\text { Ex-donor } \\
(\mathrm{n}=156)\end{array}$ & $\begin{array}{l}\text { Non-donor } \\
(n=650)\end{array}$ \\
\hline Off putting aspects specified & $47(460)$ & $15(15)$ & $37(18)$ & $47(74)$ & $53(345)$ \\
\hline Nothing off putting & $32(316)$ & $58(57)$ & $50(25)$ & $30(47)$ & $28(183)$ \\
\hline $\begin{array}{l}\text { Never bothered to give blood, no time to } \\
\text { give blood, or not got around to }\end{array}$ & & & & & \\
\hline giving blood & $10(94)$ & $1(1)$ & $5(2)$ & $8(13)$ & $12(76)$ \\
\hline Never thought of giving blood & $5(50)$ & & $1(1)$ & $1(1)$ & $7(48)$ \\
\hline Main off putting reason given: & & & & & \\
\hline Any health reasons & $20(198)$ & $2(2)$ & $19(9)$ & $20(31)$ & $24(156)$ \\
\hline Fear of needles or injections, or both & $12(114)$ & $3(3)$ & $6(3)$ & $3(5)$ & $16(102)$ \\
\hline Specific mention of dirty needles & 1 (8) & $1(1)$ & & $2(3)$ & $1(4)$ \\
\hline Too old or too young & $7(70)$ & $3(3)$ & $2(1)$ & $13(20)$ & $6(42)$ \\
\hline $\begin{array}{l}\text { Bad experience (personal, hearsay, or } \\
\text { expected) }\end{array}$ & $5(49)$ & $6(5)$ & $9(4)$ & $7(11)$ & $4(27)$ \\
\hline Possibility of developing AIDS & $5(53)$ & 1 (1) & $4(2)$ & $5(9)$ & $6(41)$ \\
\hline
\end{tabular}

« Sixteen people could not be allocated donor state but were included in total. Spontaneous response multicode analysis was used to analyse results. a psychologist or group moderator they were asked to discuss in depth the subject of interest. This technique is derived from market research ${ }^{1}$ but is now being more widely adopted within the social sciences. ${ }^{23}$ It overcomes many of the disadvantages of methods that use questionnaires, especially non-sampling errors such as lack of depth in probing. Leathar and Roberts have previously described this method. ${ }^{+}$

In our study 16 group discussions were conducted. All the groups, except two groups of non-donors, comprised blood donors in predefined socioeconomic categories with a range of donating experience. Thus current donors (those who had donated in the previous two years), lapsed donors and ex-donors (those who had not donated for two and four years respectively), and non-donors were all included (table III). The Scottish National Blood Transfusion Service provided suitable names and addresses after having notified the potential respondents about the survey. These people were then contacted by professional market research interviewers and invited to attend the group discussions in a private house. Each discussion lasted about an hour and a half. Respondents were paid a standard fee for participating, and the discussions took place at the end of 1987 and early in 1988. The interviews were loosely structured, with considerable time being devoted to a general discussion about attitudes to blood donation and to AIDS in isolation before the existence of any relation between the two was discussed. Perceptions about the response of the transfusion service to the problem of AIDS both before and after donation and reactions to related material from the media were also discussed.

\section{Results}

The results of the quantitative survey showed that AIDS was not an important off putting aspect of donating blood, being mentioned spontaneously by only $5 \%$ of the respondents (table IV). Aspects that received greater mention were health reasons $(20 \%)$, fear of needles (12\%), and apathy (10\%). Furthermore, although lapsed donors, ex-donors, and non-donors tended to be increasingly more likely to find something off putting about blood donation $(37 \%, 47 \%$, and $53 \%$ respectively) when compared with current donors (15\%), this tendency did not emerge to any appreciable extent for the specific mention of AIDS.

Similar findings emerged from the qualitative survey. The discussions showed a range of encouraging and discouraging factors, the balance of which influenced the decision to donate. This balance varied over time and between people.

Motivating factors included group pressure, direct contact with the need for blood, feelings of social duty, and emotional rewards from having donated. This las benefit was particularly emphasised by donors. They took pride in performing an important public service and giving blood made them feel worthy and wholesome. Discouraging factors included fear, apathy, inconvenience, and the person's state of health. Fears varied in focus and intensity and included a fear of needles, of clinical atmospheres, of intrusion into the body, and of something going wrong. Importantly, as in the quantitative survey, AIDS was seldom mentioned in this context.

This apparent indifference to AIDS shown spontaneously was confirmed by prompted data. Thus most of the respondents in the quantitative survey thought that it was unlikely (48\% not at all likely and $27 \%$ no very likely) that they could develop AIDS from giving blood (table V). Furthermore, the mean score for lapsed donors and ex-donors (1.46 and 1.52 respectively) did not differ significantly from that of current donors $(1 \cdot 48)$. Non-donors were more likely 
TABLE V-Respondents' thoughts about likelihood of developing AIDS from giving blood scored from 1 to 4 . Values are percentages (numbers) of respondents. Weighting was applied during analysis of data

Donor state ${ }^{\star}$

\begin{tabular}{lccccc}
\cline { 5 - 6 } \multicolumn{1}{c}{ Likelihood (score) } & $\begin{array}{c}\text { Total } \\
(\mathbf{n}=976)\end{array}$ & $\begin{array}{c}\text { Current donor } \\
(\mathbf{n}=98)\end{array}$ & $\begin{array}{c}\text { Lapsed donor } \\
(\mathbf{n}=50)\end{array}$ & $\begin{array}{c}\text { Ex-donor } \\
(\mathbf{n}=156)\end{array}$ & $\begin{array}{c}\text { Non-donor } \\
(\mathbf{n}=650)\end{array}$ \\
\hline Very likely (4) & $4(37)$ & $5(5)$ & & $1(1)$ & $5(31)$ \\
Quite likely (3) & $15(150)$ & $2(2)$ & $8(4)$ & $10(16)$ & $19(122)$ \\
Not very likely (2) & $27(262)$ & $28(28)$ & $29(15)$ & $27(43)$ & $26(171)$ \\
Not at all likely (1) & $\mathbf{4 8 ( 4 6 4 )}$ & $63(62)$ & $62(31)$ & $56(87)$ & $43(277)$ \\
Do not know (0) & $6(63)$ & $2(2)$ & & $7(11)$ & $7(48)$ \\
\hline Mean score & 1.74 & 1.48 & 1.46 & 1.52 & 1.85
\end{tabular}

« Sixteen people could not be allocated donor state but were included in total.

than current donors to think that they could develop AIDS from donating blood (mean scores 1.85 and 1.48 ), but again the difference was not significant. Similarly, when prompted in the group discussions, respondents denied the risk of developing AIDS from giving blood. There was, for example, widespread awareness that new needles and equipment were used for each donor.

Nevertheless, both studies also showed some uncertainty among respondents about the relation between AIDS and blood donation. Thus in the quantitative work $19 \%$ thought it quite $(15 \%)$ or very likely (4\%) that AIDS could be caught from giving blood. In the group discussions indicators of uncertainty were apparent but more subtle. For example, some respondents connected AIDS with blood donation because of the images of dirty needles transferring contaminated blood seen in anti-AIDS advertising.

Of greater prominence than any concern about catching AIDS from giving blood was a clear reluctance and distaste for considering the issue personally. Pressure to do so aroused fear and resentment. Respondents were afraid of having the virus, of finding out that they had the virus, and of other people thinking that they had the virus. They resented any implication that they had a risky lifestyle (especially older people) and that their donation of blood might be a source of contamination. When discussing the Scottish National Blood Transfusion Service's printed material designed to discourage those with high risk behaviour from giving blood it became clear that respondents generally ignored the section on AIDS, seeing it as a necessary precaution to stop other undesirable people from donating but not as personally relevant. Its only effect on the respondents was to create a negative and depressing impression. When it was suggested in the groups that the messages about potential contamination were aimed at all donors, including them, their reaction was extremely unfavourable. It provoked all the negative emotions described above and caused great resentment.

In contrast, respondents thought that material aimed at them should be positive in tone-for example, thanking them for being donors and reinforcing their good feelings about giving blood. If AIDS was mentioned the only message that would interest them was reassurance that they could not get AIDS from giving blood.

\section{Discussion}

This survey provides little evidence to suggest that an overt fear of contracting HIV is discouraging blood donation. Few people spontaneously mentioned this issue when asked to list off putting aspects of donation, and lapsed donors, ex-donors, and non-donors were no more inclined to do so than current donors. Furthermore, the balance of factors determining donation has changed little since similar research was conducted in 1984, before AIDS had become an important public issue (S G MacAskill et al, unpublished data). Finally, most people, especially donors, denied that giving blood carried any risk of HIV infection.

Nevertheless, the survey did show a sharp contrast between people's feelings about AIDS and those about blood donation. On the one hand, AIDS is an unpleasant, threatening issue that carries implications about lifestyle that many find unacceptable; on the other hand, blood donation has positive associations, many donors seeing it as a worthy and wholesome activity. These positive associations have also been reported in recent American research. ${ }^{5}$ This contrast between AIDS and blood donation is thrown into relief by the process of screening for HIV, which requires potential donors to consider their personal risk from AIDS. Furthermore, the Scottish National Blood Transfusion Service's publicity designed to encourage this process has adopted a negative approach. It has concentrated on the worst aspects of the AIDS issue, emphasising who should not give blood rather than encouraging those who should donate and rewarding those who do donate blood.

Thus the issue of AIDS does seem to be affecting the numbers of blood donors but not because of any direct fear of infection. Its influence is indirect as it undermines the positive associations with giving blood and has stimulated the production of publicity campaigns that discourage rather than encourage donation.

Any attempt to redress the imbalance by reducing the impact of the screening procedures is fraught with danger. To be effective all donors must be able to understand the screening questions and apply them to their own circumstances. Further research is needed to find out methods of effective screening with maximum acceptability to donors. Meanwhile a large scale publicity drive is urgently needed to emphasise the positive benefits and rewards from blood donation. Unless this is started the transfusion services can expect a further fall in public support. In addition, the conduct of blood donor sessions should be looked at to ensure that the pleasant and positive feelings associated with donation are appropriately reinforced.

We thank the staff at the regional blood transfusion centres in Glasgow, Edinburgh, and Aberdeen for all their help.

1 Atkin C. Research evidence on mass mediated health communication campaigns. In: Nimmo D, ed. Communications yearbook No 3. New Brunswick, New Jersey: Transaction Books, 1979:655-68.

2 Cooper P, Branthwaite A. Qualitative technology: new perspectives on measurement and meaning through qualitative research. In: Proceedings of the Market Research Society's 20th annual conference. Brighton: Market Research Society, 1977:79-92.

3 United States Department of Health and Human Services. Pretesting health communications. Washington, DC: DHHS, 1980. (DHHS publication No (NIH) 83-1493.)

4 Leathar DS, Roberts MM. Older women's attitudes to breast disease, self examination and screening facilities: implications for communication. BrMed f 1985;290:668-70.

5 American Association of Blood Banks. Public opinion poll reveals surprising views. Blood Bank Week 1988 June 17:1-4.

(Accepted 31 fanuary 1989) 